The main obstacle to the achievement of a full measure of research activity in industry is not to be found in any hostility to the scientific worker or in any sense of complacency in industry, but in the scientific man-power situation. A healthy industry requires that far more scientific workers should be trained in the future than in the past. The larger universities are already as large as is consistent with efficiency, and it follows therefore that increased facilities must be created by enlargement of the smaller provincial universities and by the establishment of technical educational institutions in industrial areas where no university or technical college exists.

The Government is alive to the situation and has established the machinery for reviewing and, it is to be hoped, remedying the existing state of affairs. The problem of providing adequate facilities for technical and scientific training includes the provision of sufficient and qualified teachers. Since, under the best conditions, the teaching staff of a technical institution should be in close contact with technicians and scientific men engaged in industry, it is highly desirable that the remuneration of the teachers should compare favourably with that received by their industrial colleagues; and, in fact, suitable teachers will not be forthcoming unless such is the case. The last clause of the resolution is important, for past experience has shown that when industry has interested itself in local educational matters and has supported the local education authority, the battle for the provision of technical educational facilities peculiar to local requirements has been more than half won. Whatever Government scheme for technical education is fortheoming, its application to particular areas will undoubtedly be influenced by a display of stimulating interest on the part of local industry.

\section{THE ROYAL ACADEMY, 1946}

\section{By DR. A. T. HOPWOOD}

British Museum (Natural History)

" $\mathrm{C}$ VRITICS have always been people less suscepA tible than other men to the contagion of art. For the most part they are able writers, educated and clever, but with their capacity for being infected by art quite perverted or atrophied." Tolstoy's diatribe against crities was inevitably brought to mind by the present Summer Exhibition at the Royal Academy. The first impression was disappointing, and the critic had to determine where the fault might lie. Subsequent impressions were no more favourable; it proved distressingly easy to spot artist after artist without recourse to the catalogue. Another source of disquiet was the obvious dependence of many exhibitors on French artists of a generation or so ago. Neither of these is a healthy sign : the first indicates a tendency to fixity of style, to painting to a formula, and the second a lack of originality. It seemed likely, therefore, that there might be something wrong with the exhibits after all.

Now Tolstoy propounded a muddled variant of the generally held view that the fruits of an artist's labours constitute a work of art only in so far as they convey his emotions to the spectator; he also held the opinion, more popular than ever in certain circles to-day, that "art should belong to the people". Hence his high opinion of the untutored peasant as a judge of art. If such indeed were the case, the artistic value of "Flower Piece" by E. Wadsworth (No. 665), or of "Objects in a Scene of Devastation" by H. A. Lunn (No. 657) could not be rated very highly, for, whatever may have been the emotions of the artists as they painted, they are completely hidden from the vulgar perception. On the other hand, "Girl in Grey" by J. B. Souter (No. 454) would obviously be of higher artistic value, because a picture of a pretty girl standing with one hand resting on the mantelshelf seems to tell its own story. The falsity of this reasoning is not immediately apparent. That Mr. Souter's painting is of considerable artistic merit arises, not from the subject, but from the artist's skill in drawing and design, and from his sense of colour, and that this is the real explanation is shown by his other picture, "Wood Wind" (No. 520 ), in which there is no pretty girl to disturb the judgment.

But there is another and more puritanical, more 'scientific' theory of art. More puritanical because the emotions are heavily discounted, more 'scientific' because there is an elaborate classification of the different types of artists ranging from the 'original architectural artist' down to the 'venal popular artist'. R. H. Wilenski, the author of this theory, holds that a work becomes a work of art when it has been honestly and competently passed by its author as having satisfied his aims. From this fact alone it possesses an intrinsic value according to the artist's position in the classified scheme. There is also an independent and acquired value which arises from the reaction of the spectator. It then becomes the critic's function to endeavour to explain the artist's aim, and not to describe his own emotions.

Clearly, the intrinsic value is something peculiar to the picture and personal to the artist, and the spectator must assume that each of the exhibits has been honestly approved by the artist as having the primary intrinsic value; but the critic's task is not made any easier thereby for he has to attempt to explain something which is personal to another. More especially is this true of the present show, which is stolen by a picture painted more than seventy years ago. "Hearts are Trumps" by Sir John Millais is an example of a mastery which to-day is practically extinct. To dismiss this picture as 'popular romantic art' is entirely beside the point ; it displays a knowledge and craftsmanship which are absent from the majority of the modern works, and those who affect to despise craftsmanship should remember Renoir's advice, "Be a good craftsman first of all ; that won't prevent you having genius".

Good craftsmanship I take to include good drawing and good design, as well as good painting, but all three are rarely to be found on one and the same canvas. The weakest spots are usually drawing and design. One example of good craftsmanship is "Shipyard at Palma in Majorca" by C. Muncaster (No. 467), another is "Life Study" by Erica Suttill (No. 482). On the other hand, there are many works which by reason of their heavy impasto cannot be regarded as good painting. This is not to say that the artist has not achieved what he set out to do, nor that the result is bad, but merely that heavy impasto affords lodgment for dirt and dust, and that one regrets a pleasant sketch such as "Chilham Mill" by James Doxford (No. 8) should carry within itself the seeds of its own decay.

As usual, there is a large number of flower pieces of varying merit, and nearly as many still lifes, 'still life with trimmings' as it were, but only on 
artist is at all original in his approach to the subject. For this reason "Flints and Fungus" (No. 180) and "Apple Log" (No. 221) are worthy of examination. Both are by Dudley Holland and neither is particularly well hung.

"Concarneau Harbour" by Murray Urquhart (No. 283) is painted in an impressionist manner, and with an impressionist palette. It illustrates once again how well suited this method is for outdoor subjects. A more modern way of dealing with buildings and trees is seen in "Houses by the New River" by Greta Ward (No. 88) and "West Hill, Highgate Village" by Peter Lowry (No. 864). In these there is little of the traditional recession of the planes; instead the artists give us a statement of the relationship of the various objects to each other when projected into one plane, the plane of the canvas or paper. Another picture of some interest is "Chelsea Terrace: Evening" by Robin Clifford (No. 176) which is in complete contrast to the two just mentioned. Where they tend to romance this tends to the factual, where they are relatively gay in colour this is drab, but the idiom is modernistic and not very comfortable.

One of the chief charms of water-colour drawings is that they possess a freshness and sparkle unobtainable in any other medium. Whether applied as washes or as blobs, water-colours are pre-eminent for rapid sketches; but they demand a skill and knowledge which will enable the artist to lay on the correct colour by first intention in the proper place, and afterwards to leave it alone. Any other way is apt to destroy the transparency of the medium and to lead to a muddiness which seems to be creeping back into modern practice. This is coming about through a revival of the old custom of applying an overall wash of yellow to the paper before starting work. Certain subjects benefit from this method, but as a general rule it leads to an undesirable lowering of tone. A more modern technique is to make slight sketches in pen or pencil and to do no more than indicate the artist's awareness of colour by means of occasional plain washes. To this class belong "Back Gardens" by Julia Morley (No. 748), and "Fête" by C. Bendall (No. 787) who has succeeded in conveying the movement of the dancing crowd in a convincing way.

The drawings and etchings in Gallery IX are pleasantly mixed. They range from the lively naturalism of Winifred Austen's "Marsh Tit" (No. 1054) through C. F. Tunnicliffe's "Wood Owl" (No. 1077) to "Nether Warden" by Clifford Webb (No. 1073) and "Rock Pool" by A. S. H. Mills (No. 1079). A drawing of "Professor J. T. Randall" by H. A. Freeth (No. 1008 ) is among the best of the portraits.

Architecture is not prominent this year: the number of exhibits is small compared with what one might have expected at a time when reconstruction is so much to the fore, but this is possibly a reflexion of the prevailing uncertainties of the situation. The majority of the plans are for public buildings. Plans for dwelling-houses are rare, but there are several blocks of flats, and housing schemes for local authorities.

Some of the animal studies in the sculpture gallery are good. I particularly liked "Gnu" by H. W. Palliser (No. 1172), "Ocelot" by Pamela Ascherson (No. 1255) and "Sleeping Cat" by W. G. Simmonds (No. 1262). Young artiodactyls seem to have an attraction for sculptors at the present time. This year we have "Lambs" by Rosamund Fletcher (No. 1202), "Fawn" by Faust Lang (No. 1205) and "Water Hole" by Alfred Oakley (No. 1208). The animal in the last-named piece has a tail which closely resembles that of a horse, and in this feature bears no resemblance to the young of any known ruminant.

Taken as a whole, this year's exhibition is disappointing. One has the feeling that artists, like other people, are tired and in need of inspiration rather than already in possession of it, or, at least, that they have not yet adjusted themselves to the conditions which are the legacy of war. To this many of them would possibly retort with Renoir's saying, "I have no theories; I paint for the sake of painting"'. They are the ones who, I suggest, will most rapidly find themselves again.

\section{NEW FOREIGN MEMBERS OF THE ROYAL SOCIETY}

A S announced briefly in Nature of May 18, p. 651, the following have been elected foreign members of the Royal Society :

\section{Dr. Herbert S. Gasser}

DR. Herbert S. GASSER, director of the Rockefeller Institute of New York, gave a new impetus to the physiology of the nervous system by his development of the technique of valve amplification and of recording with the cathode ray oscillograph, and by the exact analysis of the nerve action potential which he carried out with Prof. J. Erlanger. Making full use of the extended range of measurement, Gasser and Erlanger were able to show the composite nature of the action potential of a mixed nerve trunk and to measure the rates of conduction and the form of the electric response in the different types of nerve fibre. This work, for which they were awarded the Nobel Prize for Medicine in 1944, has led to a greatly increased understanding both of the biophysics of nerve and of the function of the different types of nerve fibre. It is now the basis of the exact studies of conduction within the central nervous system which are throwing fresh light on reflex activity.

Dr. Gasser is so well known to physiologists in Great Britain that his great personal influence and his successful direction of a famous institute need no comment. But his work for the joint war effort will be remembered, and in particular his many kindnesses to British men of science visiting the United States during the war period.

\section{Prof. Frédéric Joliot}

THE election of Prof. F. Joliot to the foreign membership of the Royal Society, at the exceptionally early age of forty-five, is a sign of the great admiration and regard in which he is held by his British colleagues. Prof. Joliot occupies a place in the contemporary world which has no exact parallel; there must be few who can combine eminence as a scientific worker, administrator and man-of-affairs in such a high degree. As an experimental physicist he has shown the most fertile imagination and skill. Together with his wife, Irene Curie, he discovered 